\title{
Strong-motion observations recorded in Strategic Public Buildings during the 24 August 2016 Mw 6.0 Amatrice (Central Italy) Earthquake
}

\author{
Chiara Ladina*, Simone Marzorati, Giancarlo Monachesi, Marco Cattaneo, \\ Massimo Frapiccini, Viviana CASTELLI \\ Istituto Nazionale di Geofisica e Vulcanologia, Italy \\ *chiara.ladina@ingv.it
}

\begin{abstract}
The Marche Region, in collaboration with INGV, has promoted a project to monitoring public strategic buildings with permanent accelerometer installed at the base of the structures. Public infrastructures play a primary role to maintain the functionality of a local community. Information about vibratory characteristics of the building and subsoil, in addition to the seismic instrumental history that describe the seismic shaking at the base of the structure are collected for each buildings. The real-time acquisition of seismic data allows to obtain accelerometric time history soon after the occurrence of an earthquake. The event of 24 August 2016 in Central Italy was an opportunity to test the functionality of this implemented system. In this work the parameters obtained from strong motion data recorded at the base of the structures were analyzed and the values obtained were inserted with some empirical relationships used to provide intensity microseismic values and damage indices.
\end{abstract}

\section{INTRODUCTION}

$\prod$ he real-time acquisition of seismic data allows to define quickly the location and focal parameters of an earthquake, through the inversion of the data recorded directly on the surface by a seismic network. One of the immediate benefits is to be able to inform the civil protection authorities about the location and size of the earthquake, and its potential effects, in order that the procedure of intervention and relief are started as soon as possible. So, it is important to determine in a short time the seismic event impact on the territory, assuming mainly the areas with damage to civil and public infrastructures. 
Public infrastructures, such as municipal buildings, hospitals, schools, police stations, firehouses, play a primary role in maintaining the functionality of a local community. For this reason, a project to monitor strategic public buildings, in the framework of the European Holistic project (N. 1 st / 0001 project code, cofunded by European - Instrument for PreAccession Assistance, IPA Adriatic Cross-Border Cooperation) started in the year 2014 by the Functional Centre of the Integrated Security Policies and Civil Protection Department - Marche Region (DPISPC) and the Ancona branch of National Institute of Geophysics and Volcanology (INGV). Currently in the Marche Region 14 testbuildings are monitored, through accelerometers installed at the base of the structures; in some cases the project made use of already installed low-cost accelerometers, in other cases new installations were required. Seismic data are transmitted in real time and integrated into the seismic network RESIICO and then used for standard procedures of seismic monitoring [Ladina et al., 2015].

This type of monitoring is not exhaustive for knowing the real dynamic behavior of structures during the seismic event and the damage of the structure, obtainable only by means of instruments installed in all parts of the building, as in the standard for the Observatory of Structures [Dolce et al., 2015]. On the contrary, in this project, the aim is to deduce the likely effect suffered by the structure from the ground shaking at the site. The objective is monitoring considerable number of structures spread all over the territory, in order to identify, in a short time after the event, its impact on the territory and the possible disaster areas.

The earthquake of 24 August 2016 in central Italy was an opportunity to test the functionality of this implemented system by analyzing the strongmotion parameters obtained from strong motion data recorded at the base of the structures. In this work we make use of some empirical relationships to provide intensity macro seismics values and damage indices.

\section{II.BUILDING MONITORING}

Strategic public buildings are important to maintain the administrative and social functions of a community. After catastrophic events such as earthquakes, it is necessary to estimate in a short time which is the impact and the effect on the territory, identifying the critical issues. The damage of strategic public buildings aggravates the emergency situation resulting from a destructive seismic event. Being able to estimate as soon as possible how many strategic public buildings may have been damaged without directly detect the effects on the territory, contributes to program the civil protection assistance through a rapid response.

The Marche Region, in collaboration with INGV, has promoted a project to enhance the accelerometer monitoring to get a better estimate of the seismic events in the region. Some accelerometers have been installed at the base of public buildings in order to take advantage of $\mathrm{Wi}$ Fi transmission networks and internet inside the structures and so integrate accelerometers in the seismic monitoring network [Monachesi et al., 
2013]. Later, these accelerometers have been used, in addition to others, to develop seismic monitoring of strategic buildings in the European project Holistic. On each of these buildings, environmental seismic noise measurements were performed to identify the fundamental periods of oscillation of the structures [Ladina et al., 2015]. At present 14 accelerometers are installed at the base of strategic public buildings (Figure 1 and Table 1). The acquisition system is GAIA2 and sampling rate $200 \mathrm{sps}$ for all stations. In 12 cases, the strong motion stations are equipped with MEMES accelerometers (Colibrys SF3000), cheaper than the standard force-balance accelerometers but anyway assuring a dynamic range adequate to record moderate and strong seismic events. In 2 cases (MNTP and MRSC) the strong motion stations are equipped with accelerometers Episensor FBA ES-T.

Then, in Table 1 the Eurocode 8 subsoil classes (EC8geo) [CEN, 2004] and topographic index (EC8topo) is assigned to the stations. EC8geo is based on lithological and surface geology and classes are assigned according to Eurocode8 Part1 (class A for rock or other rock-like geological formation $\left(\mathrm{V}_{\mathrm{s} 30}>800 \mathrm{~m} / \mathrm{s}\right)$; other classes (B to $\mathrm{E}$ ) for deposits with $\mathrm{V}_{\mathrm{s} 30}$ descending). EC8topo is defined in the Italian Technical Norms [NTC, 2008], a simplified classification of landforms divided into four categories (T1 flat surface with $\mathrm{i} \leq 15^{\circ}$; T2 slopes with average inclination $\mathrm{i}>15^{\circ}$; then, reliefs with ridge top width much smaller than the base, and average inclination $15^{\circ} \leq \mathrm{i} \leq 30^{\circ}$ for $\mathrm{T} 3$ and $\mathrm{i}>30^{\circ}$ for $\mathrm{T} 4$ ). Stations have been classified for these parameters in the project Holistic collecting the details of fundamental geological information and geotechnical investigations.

The continuous data are transmitted and centralized to contribute to the monitoring of seismicity and then to locate and determine the parameters of earthquakes. Continuous recording is useful to collect an instrumental database of ground motion accelerations suffered the structure, thus constructing a seismic history of all events undergone by the building. Potentially, the data may be available after the identification of the seismic event as a result of the following procedures: detection, windowing, fine picking of arrival times [Cattaneo et al., 2016] and calculating parameters. These procedures, already active at the headquarter of INGV-Ancona, would make the data available after about 20 minutes. In particular, the aim is to store up the memory of all events that generated an acceleration greater than $0.001 \mathrm{~g}$ at the base of the structure; the value is the threshold beyond which the earthquake can be perceived by people, as shown by some empirical relationships [Faenza and Michelini, 2010; Wald et al., 1999]. It is possible to estimate the impact sustained by a structure at its base, even if it is not possible to know the damage, and then hypothesize possible damage or immediately recommend a check of the structure. The evaluation takes place either by empirical relationships that provide an intensity degree, or by fragility curves that provide probability values for different levels of damage from strong-motion parameters. 


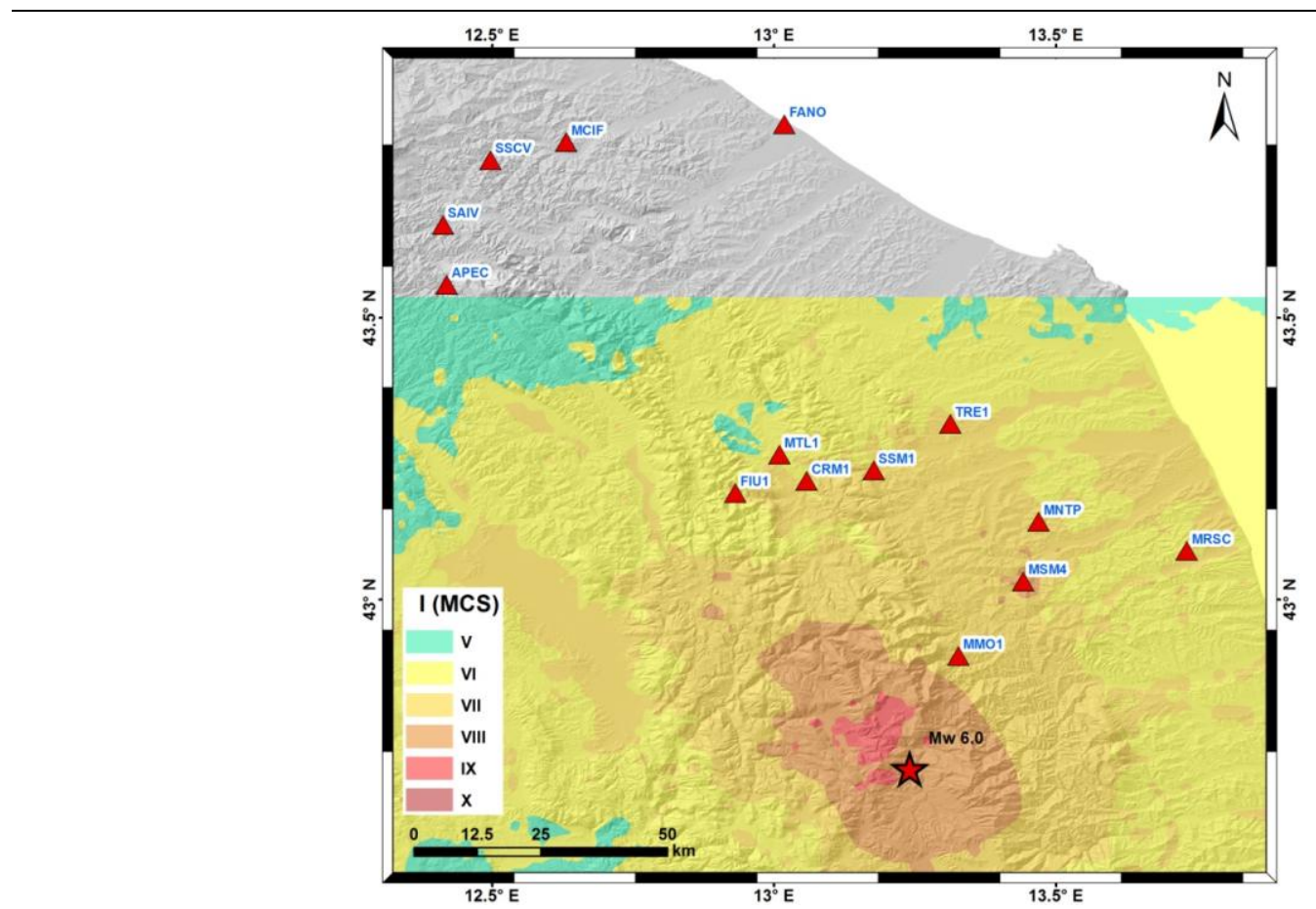

Figure 1. Map of the stations at the base of the strategic buildings (red triangles). Epicenter of 24 August 2016 (red star). MCS Intensity map modified by ShakeMap available online (http://shakemap.rm.ingv.it). The ShakeMap available does not cover the northern part of Marche Region.

\section{DATA ANALYSIS OF THE 24 AUGUST, 2016 AMATRICE EARTHQUAKE}

During the event of August 24, 2016 01:36 UTC of magnitude Mw 6.0 that struck central Italy, 13 of the 14 strong motion stations were active. The distances of the stations from the epicentral area range from 25 to $135 \mathrm{~km}$. In Figure 2 the waveforms of the 6 accelerometric stations that registered the greater acceleration peaks are shown. The data transmission of three seismic stations (MSM4, MTL1 and MCIF) is not complete because of a power supply fault. For the station MSM4 the recording lasts up to few seconds after the arrival of the $S$ phase, but stop before the end of the most energetic part of the event. For the station MTL1 the recording includes the most energetic part of the event and stop 10 seconds after the $S$ phase where the amplitude are already decaying. We are confident that the PGA calculated value is reliable for MTL1 station. For all accelerometric data some strong-motion parameters were calculated, including Peak Ground Acceleration (PGA), Peack Ground Velocity (PGV), Housner Intensity (HI). The accelerometric waveforms were filtered with bandpass filter between $0.2-20 \mathrm{~Hz}$. Table 2 shows the results obtained for each station. 
ANNALS OF GEOPHYSICS, 59, Fast Track 5, 2016; DOI: 10.4401/ag-7194

\begin{tabular}{|c|c|c|c|c|c|c|c|c|}
\hline CODE & MUN & DEPI & $\mathrm{AZ}$ & BUIL & TYPOL & N_F & EC8geo & EC8topo \\
\hline MMO1 & Monte Monaco & 24 & 19 & town hall & Stone and bricks & 3 & A & $\mathrm{T} 2$ \\
\hline MSM4 & $\begin{array}{l}\text { Monte San } \\
\text { Martino }\end{array}$ & 41 & 25 & school & Reinforced concrete & 3 & $\mathrm{~B}$ & $\mathrm{~T} 2$ \\
\hline MNTP & Montappone & 52 & 21 & town hall & Solid bricks and lime mortar masonry & 3 & $\mathrm{~B}$ & $\mathrm{~T} 2$ \\
\hline CRM1 & Castelraimondo & 58 & 346 & town hall & Solid bricks and lime mortar masonry & 3 & $\mathrm{C}$ & $\mathrm{T} 1$ \\
\hline MRSC & Moresco & 59 & 43 & town hall & Stone and bricks & 3 & $\mathrm{C}$ & $\mathrm{T} 2$ \\
\hline SSM1 & $\begin{array}{l}\text { San Severino } \\
\text { Marche }\end{array}$ & 59 & 355 & town hall & Stone masonry and solid bricks & 4 & $\mathrm{C}$ & $\mathrm{T} 1$ \\
\hline FIU1 & Fiuminata & 60 & 335 & town hall & $\begin{array}{l}\text { Partially dressed stone masonry with } \\
\text { good bonding }\end{array}$ & 2 & A & $\mathrm{T} 2$ \\
\hline MTL1 & Matelica & 64 & 343 & town hall & Solid bricks and lime mortar masonry & 3 & $\mathrm{C}$ & $\mathrm{T} 1$ \\
\hline TRE1 & Treia & 68 & 5 & town hall & Solid bricks and lime mortar masonry & 3 & A & T3 \\
\hline APEC & Apecchio & 115 & 325 & town hall & Stone masonry & 3 & $\mathrm{C}$ & $\mathrm{T} 1$ \\
\hline SAIV & $\begin{array}{l}\text { Sant'Angelo in } \\
\text { Vado }\end{array}$ & 126 & 328 & town hall & Stone masonry and bricks & 4 & A & $\mathrm{T} 1$ \\
\hline FANO & Fano & 128 & 352 & town hall & Reinforced concrete & 4 & $\mathrm{C}$ & $\mathrm{T} 1$ \\
\hline MCIF & $\begin{array}{l}\text { Montecalvo in } \\
\text { Foglia }\end{array}$ & 133 & 338 & town hall & $\begin{array}{l}\text { Partially dressed stone masonry with } \\
\text { good bonding }\end{array}$ & 2 & $\mathrm{~B}$ & $\mathrm{~T} 2$ \\
\hline SSCV & Sassocorvaro & 133 & 333 & town hall & Reinforced concrete & 2 & A & $\mathrm{T} 2$ \\
\hline
\end{tabular}

Table 1: Abbreviations, coordinates and technical characteristics of sites. Station Code (CODE), Municipality (MUN), Epicentral Distance (DEPI, km), Epicenter/station azimuth (AZ, degrees from N), Building type (BUIL), Typology of building (TYPOL), Number of floors (N_F), Soil (EC8geol) and morphological (EC8topo) categories. Information about buildings from Holistic project.
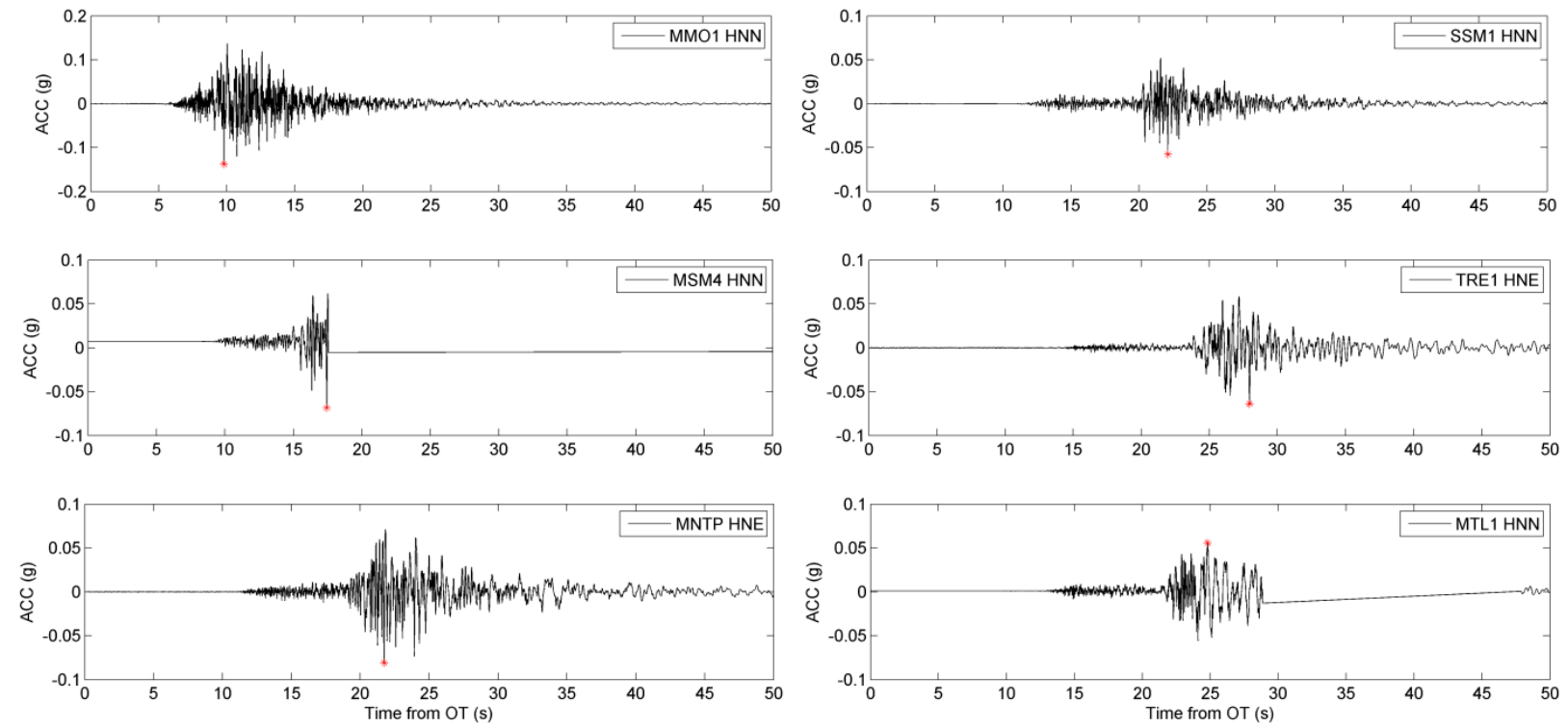

Figure 2. Waveforms with greatest acceleration peaks. 
ANNALS OF GEOPHYSICS, 59, Fast Track 5, 2016; DOI: 10.4401/ag-7194

\begin{tabular}{lcccccc}
\hline CODE & HYPOD & PGAmax & PGAmean & PGVmax & PGVmean & HImax \\
MMO1 & 24 & 138.48 & 127.233 & 6.669 & 5.880 & 20.552 \\
MSM4 & 41 & 66.732 & 64.245 & 3.284 & 3.260 & 7.417 \\
MNTP & 53 & 80.575 & 75.939 & 4.309 & 3.626 & 12.793 \\
MRSC & 60 & 24.97 & 21.133 & 2.743 & 2.449 & 8.584 \\
SSM1 & 60 & 59.684 & 35.175 & 2.589 & 1.761 & 7.363 \\
FIU1 & 61 & 40.386 & 34.350 & 1.652 & 1.526 & 4.467 \\
MTL1 & 65 & 56.316 & 52.710 & 6.048 & 4.593 & 21.786 \\
TRE1 & 69 & 68.233 & 64.952 & 5.743 & 4.457 & 16.855 \\
APEC & 117 & 8.38 & 7.206 & 0.897 & 0.795 & 3.166 \\
SAIV & 127 & 6.587 & 6.153 & 0.554 & 0.503 & 2.049 \\
FANO & 130 & 22.764 & 20.770 & 2.769 & 2.750 & 11.015 \\
MCIF & 134 & 3.270 & 3.151 & 0.257 & 0.227 & 0.864 \\
SSCV & 135 & 7.787 & 7.717 & 0.889 & 0.741 & 3.332 \\
\hline
\end{tabular}

Table 2: Results obtained for seismic stations. Station code (CODE), Hypocentral distance (HYPOD, Km), maximum Peak Ground Acceleration of horizontal components (PGAmax, cm/s^2), geometric mean of Peak Ground Acceleration of horizontal components (PGAmean, $\mathrm{cm} / \mathrm{s}^{\wedge} 2$ ); maximum Peak Ground Velocity of horizontal components (PGVmax, $\mathrm{cm} / \mathrm{s}$ ), geometric mean of Peak Ground Velocity of horizontal components (PGVmean, cm/s), maximum value of horizontal components of Housner Intensity (HImax, cm).

\section{INTENSITY ESTIMATES STARTING FROM STRONG- MOTION PARAMETERS}

It is possible to apply some empirical relationships to estimate the intensity at the site and hypothesize a possible damage scenario. This information can be used as indicator to decide where to focus the investigation and assessment of damage, knowing the strong-motion parameters collected to the base of the structures. As a first test, the relationships of Faenza and Michelini [2010] were chosen, which are currently used to provide intensity maps from the production of shake maps (shakemap.rm.ingv.it). The reports use PGA, PGV to indicate an intensity degree according to the Mercalli-Cancani-Sieberg (MCS) Scale. The maximum value of the horizontal component and horizontal geometric mean were used for the PGA and PGV estimation. Several authors [Masi et al., 2010; Pergalani et al., 1999; Decanini et al., 2002; Marcellini et al., 2004] indicate the Housner Intensity (HI) as more meaningful as damage indicator than PGA and PGV. The HI estimates were included in the Chiauzzi et al. [2012] relation obtained from the accelerometer data to the base of the buildings. The report use different coefficients for the threshold $\mathrm{HI}=0.18 \mathrm{~m}$ and refers to the European Macroseismic Scale (EMS98) Intensity Scale.

The Table 3 presents the results of intensity estimates according to various relations. Although conscious that this is maybe an oversimplification to translate in ordinal values the numeric values resulting from the relations, we have used the 
following procedure: if the value obtained is greater than half a degree and less than the lower and upper half-degree (for example, VI degree is assigned to values from 5.5 to 6.5). The intensities estimates are not always consistent between stations, even referring to different macroseismic scales, but indicate a trend. This trend is of course dependent on the distance of the stations from the epicentral area but do not respect it exactly. On average, the intensity resulting from the Faenza and Michelini [2010] regression are greater than those obtained by Chiauzzi et al. [2012]. The building that may have been affected to a degree $\geq$ VI, and therefore potentially damaged for all relationships, is the nearest station (Monte Monaco, station code MMO1), about $20 \mathrm{~km}$ from the epicenter.

This building was evacuated because it was damaged, by order of the Mayor (26 of 31.8.2016, prot.3849 / 2016). The next-to-last building (Monte San Martino, station code MSM4), whose distance from the epicenter is double than that of the MMO1, has an uncertain situation.

\begin{tabular}{lcccccc}
\hline CODE & $\begin{array}{c}\mathrm{I}_{\mathrm{EMS}} \\
(\mathrm{HI})\end{array}$ & $\begin{array}{c}\mathrm{I}_{\mathrm{MCS}} \\
\left(\mathrm{PGA}_{\mathrm{mh}}\right)\end{array}$ & $\begin{array}{c}\mathrm{I}_{\mathrm{MCS}} \\
\left(\mathrm{PGA}_{\mathrm{gm}}\right)\end{array}$ & $\begin{array}{c}\mathrm{I}_{\mathrm{MCS}} \\
\left(\mathrm{PGV}_{\mathrm{mh}}\right)\end{array}$ & $\begin{array}{c}\mathrm{I}_{\mathrm{MCS}} \\
\left(\mathrm{PGV}_{\mathrm{gm}}\right)\end{array}$ & $\begin{array}{c}\mathrm{I}_{\mathrm{MCS}} \\
\left(\mathrm{PGA}_{\mathrm{sh}}\right)\end{array}$ \\
MMO1 & 6 & 7 & 7 & 7 & 7 & 7 \\
MSM4 & 5 & 6 & 6 & 6 & 6 & 8 \\
MNTP & 5 & 7 & 7 & 7 & 6 & 7 \\
MRSC & 5 & 5 & 5 & 6 & 6 & 6 \\
SSM1 & 5 & 6 & 6 & 6 & 6 & 7 \\
FIU1 & 5 & 6 & 6 & 6 & 6 & 6 \\
MTL1 & 6 & 6 & 6 & 7 & 7 & 6 \\
TRE1 & 6 & 6 & 6 & 7 & 7 & 7 \\
APEC & 5 & 4 & 4 & 5 & 5 & \\
SAIV & 5 & 4 & 4 & 5 & 4 & \\
FANO & 5 & 5 & 5 & 6 & 6 & \\
MCIF & 5 & 3 & 3 & 4 & 4 & \\
SSCV & 5 & 4 & 4 & 5 & 5 & \\
\hline
\end{tabular}

Table 3: Results of intensity estimates according to various relations. CODE: station code. $I_{E M S}$ (HI): intensity from HI

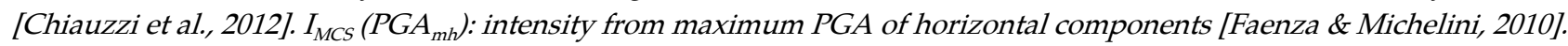
$I_{M C S}\left(P G A_{g m}\right)$ : intensity from geometric mean of the PGA of horizontal components [Faenza \& Michelini, 2010]. IMCS $\left(P G V_{m h}\right)$ : intensity from maximum PGV of horizontal components [Faenza \& Michelini, 2010]. I $I_{M C S}\left(P G V_{g m}\right)$ : intensity from geometric mean of the PGV of horizontal components [Faenza \& Michelini, 2010]. $I_{M C S}\left(P G A_{\text {sh }}\right)$ punctual values of intensity obtained from shakemap in Figure 1 using Faenza \& Michelini [2010]. 
For this building are planned seismic upgrading work although during this earthquake it had no serious damage but only cracks at the seismic joint. Its seismic data are incomplete and the peak of the events could not be transmitted. HI is then reduced by the lack of a part of the waveform; the indicated intensities may be considered a lower limit. For the group of stations between 50 and 70 $\mathrm{km}$ the intensity response range from VI to VII degree according to Faenza and Michelini [2010] and from V to VI degree according to Chiauzzi et al. [2012]. This range of distances probably indicates a wider area of mild but widespread damage. Finally, the group of stations situated more than $100 \mathrm{~km}$ from the epicenter, although still in areas where the earthquake was felt, are not indicated as potential damaged sites, having degree < VI according to all relationships. Following a request to the municipalities involved, it was confirmed that there was no damage to these buildings.

Starting from the characteristics of the buildings and with an estimate of vulnerability, the strongmotion parameters PGA and HI were compared with fragility curves [Rota et al., 2008a; Rota et al, 2008b; Rota et al, 2008c]. These curves indicate the probability for a particular typology of building to overcome a certain state of damage. Even if the application of the fragility curves are not directly applicable, they represent a mean vulnerability for this type of building [Rota et al., 2008a].
Figure 3 shows the results for the building of MMO1 station. The building has the following characteristics: 3 floors, the type of construction is masonry, irregular and flexible plans and without tie-rods. According to the classification of Rota et al. [2008a], the building belongs to the category IMA6. The results in Figure 3 show that considering the PGA, the building has $91 \%$ chance of passing the state of mild damage (DS1) and $58 \%$ to have exceeded the level of moderate damage (DS2). The estimates considering the HI are respectively $76 \%$ for the state DS1 and $36 \%$ for the DS2. In both cases, the probability of passing a DS1 damage remains high.

With the aim to deduce the likely effect suffered by the single structure, the example of MMO1 station shows that the approach used is more informative compared to methods that averaged / interpolated on a surface (Figure 1 and Table 3) although it can give similar results. This result is related to a precise acceleration point measurement to the ground. In fact, the municipal building was damaged, but it was an isolated case inside the residential area as shown by the $\mathrm{V}$ degree assigned by the macroseismic survey [QUEST W.G., 2016]. 

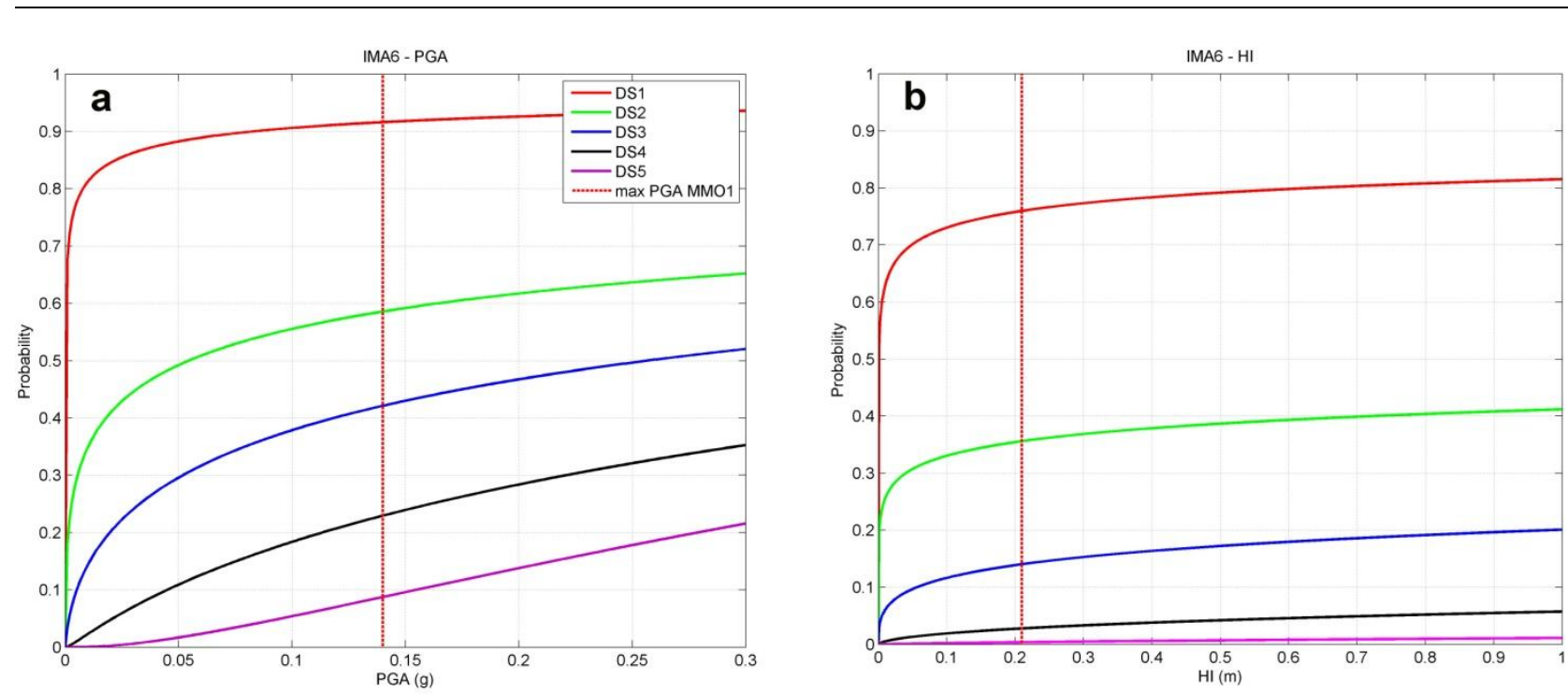

Figure 3. Results for the building of MMO1 station modified by Rota et al [2008]. a) fragility curve in PGA for the typology IMA6. b) fragility curve in HI for the typology IMA6.

\section{CONCLUSIONS}

The monitoring of strategic public buildings is important to check the status of the structures and collect instrumental seismic history and helps to evaluate the damage scenario following a destructive earthquake in the area. A monitoring approach is in testing phase, using a single accelerometer placed at the base of a structure with low-cost instrumentation, with the dual purpose of improving the estimates of shaking on the territory increasing the points at which accelerometer data are recorded and evaluating the potential damage of public buildings to contribute to the rapid response of civil protection. During the earthquake that struck Central Italy on 24 August 2016 (Mw 6.0), ground accelerations were recorded at the base of public structures with seismic instrumentation. Starting from the strong-motion parameters calculated from the waveforms, PGA, PGV and HI have been applied to the empirical relationships to estimate a degree of macroseismic intensity and a damage index through fragility curves.

For different buildings, placed in a range of 25 to $135 \mathrm{~km}$ from the mainshock epicentral area, the results of the intensity relations indicate that the only building with a high probability of being damaged is the closest one (MMO1, I $\geq \mathrm{VI}$ ), for the buildings located at the distance between 50 and $70 \mathrm{~km}$, our results indicate lower degrees of damage though in some buildings minor damage cannot be excluded. For the building which has undergone the largest impact, fragility curves corresponding to the type of construction have been applied to estimate a damage index based on an average vulnerability. For the MMO1 station, the estimates indicate a high probability of passing the state of mild damage, both for the PGA and for the HI. 
The results show that an extension of this kind of seismic monitoring throughout the region would be a useful tool to define, remotely and quickly, an approximate scenario of the impact of future earthquake on strategic public buildings. This type of monitoring, although unsuitable to determine with certainty the degree of damage

\section{ACKNOWLEDGMENTS}

The authors thank Emanuela Ercolani for helpful conversation about macroseismic survey.

The authors thank Francesca Sini and Gianni Scamuffa for information about buildings from Holistic project.

Figure 1 was created using ArcGis ${ }^{\circledR}$.

\section{REFERENCES}

[Cattaneo et al., 2016] Cattaneo, M., Frapiccini M., Ladina C., Marzorati S., Monachesi G., A mixed automatic-manual seismic catalog for CentralEastern Italy: analysis of homogeneity, 2016, Annals of Geophysics, submitted.

[Chiauzzi et al., 2012] Chiauzzi, L., Masi, A., Mucciarelli, M., Vona, M., Pacor, F., Cultrera, G., Gallovič, F. and Emolo, A. (2012). 10: 517. Bull Earthquake Eng doi:10.1007/s10518-011-9309-8.

[CEN 2004] Comité Européen de Normalisation prEN 1998-1- Eurocode 8: design of structures for earthquake resistance. Part 1: General rules, seismic actions and rules for resistance. Part 1: General rules, seismic actions and rules for buildings, 2004, Brussels. suffered by each structure, can be a useful tool for civil protection management and decision-making in emergency.

[Decanini et al., 2002] Decanini, L., Mollaioli, F. and Oliveto, G. (2002). Structural and seismological implications of the 1997 seismic sequence in Umbria and Marche, Italy. In Innovative Approaches to Earthquake Engineering, G. Oliveto (editor), Southampton, WIT Press, 229-323.

[Dolce et al., 2015] Dolce, M., Nicoletti, M., De Sortis, A., Marchesini, S., Spina, D. and Talanas, F. (2015). Osservatorio sismico delle strutture: the Italian structural seismic monitoring network, Bull. Earthquake Eng., 1-21, doi:10.1007/s10518015-9738-x.

[Faenza and Michelini, 2010] Faenza, L. and Michelini, A. (2010). Regression analysis of MCS intensity and ground motion parameters in Italy and its application in ShakeMap, Geophys. J. Int.,180,1138-1152.

[Ladina et al., 2015] Ladina, C., Marzorati, S., Frapiccini, M., Monachesi, G., Cattaneo, P., Paratore, M., Sini, F. and Ferretti, M. (2015). Attività sperimentali per l'implementazione del monitoraggio sismico di edifici pubblici nella Regione Marche. Quaderni di Geofisica INGV, 127, ISSN 1590-2595 (in Italian).

[Marcellini and Pagani, 2004] Marcellini, A. and Pagani, M. (2004). Seismic zonation methodologies with particular reference to the Italian situation. Recent Advances in Earthquake 
Geotechnical Engineering and Microzonation, A. Ansal (editor), Kluwer Academic Publisher, Printed in the Netherlands.

[Masi et al, 2010] Masi, A., Vona, M. and Mucciarelli, M. (2010). Selection of natural and synthetic accelerograms for seismic vulnerability studies on RC frames. Journal of Structural Engineering, ASCE Special Issue devoted to "Earthquake Ground Motion Selection and Modification for Nonlinear Dynamic Analysis of Structures". DOI: 10.1061/(ASCE)ST.1943541X.209.

[Monachesi et al., 2013] Monachesi, G., Cattaneo, M., Ladina, C., Marzorati, S., Frapiccini, M., Carannante, S., Ferretti, M., Sebastianelli, M., Delladio, A. and Selvaggi, G. (2013). Esperienze di monitoraggio integrato: il caso della Rete Sismometrica dell'Italia Centro Orientale, di quella Accelerometrica Marchigiana e dei suoi servizi, Quaderni di Geofisica, ISSN: 1590-2595, 106, pp.30.

[NTC, 2008] Nuove Norme Tecniche per le Costruzioni. Part 3: Categorie di sottosuolo e condizioni topografiche, Gazzetta Ufficiale n. 29 del 4 febbraio 2008.

[Pergalani et al., 1999] Pergalani, F., Romeo, R, Luzi, L., Petrini, V., Pugliese, A. and Sanò, T. (1999). Seismic microzoning of the area struck by
Umbria-Marche (Central Italy) Ms 5.9 earthquake of 26 September 1997. Soil Dynamics and Earthquake Engineering, 18, 4, 279-296.

[QUEST W. G. 2016] QUEST W.G, The 24 August 2016 Amatrice earthquake: macroseismic survey in the damage area and EMS intensity assessment, Annals of Geophysics, vol. 59, Fast Track 5, 2016.

[Rota et al., 2008a] Rota, M., Penna, A. and Strobbia, C. L. (2008a). Processing Italian damage data to derive typological fragility curves. Soil Dynamics and Earthquake Engineering, 28(10-11), 933-947.

[Rota et al., 2008b] Rota, M., Penna, A., Strobbia, C. L. and Magenes, G. (2008b). Direct derivation of fragility curves from Italian post-earthquake survey data, The 14th World Conference on Earthquake Engineering, October 12-17, Beijing, China.

[Rota et al., 2008c] Rota, M., Penna, A. Strobbia, C. L. and Magenes, G. (2008c). Derivation of Empirical Fragility Curves from Italian Damage Data, IUSS Press, Research Report Rose 2008/08. [Wald et al., 1999] Wald, D.J., Quitoriano, V., Heaton, T.H. and Kanamori, H. (1999). Relationships between peak ground acceleration, peak ground velocity, and Modified Mercalli intensity in California, Earthq. Spectra, 15(3), 557564. 